\title{
Lidil
}

Revue de linguistique et de didactique des langues

56 | 2017

Grammaires et littéracies

\section{Henri Boyer, Introduction à la sociolinguistique}

Paris, Dunod, 2017, 140 p.

Marielle Rispail

\section{CpenEdition}

Journals

Édition électronique

URL : http://journals.openedition.org/lidil/4724

DOI : $10.4000 /$ /idil.4724

ISSN : 1960-6052

Éditeur

UGA Éditions/Université Grenoble Alpes

Édition imprimée

ISBN : 978-2-37747-024-2

ISSN : $1146-6480$

Référence électronique

Marielle Rispail, « Henri Boyer, Introduction à la sociolinguistique », Lidil [En ligne], 56 | 2017, mis en ligne le 01 novembre 2017, consulté le 23 septembre 2020. URL : http://journals.openedition.org/lidil/4724 ; DOI : https://doi.org/10.4000/lidil.4724

Ce document a été généré automatiquement le 23 septembre 2020.

(c) Lidil 


\section{Henri Boyer, Introduction à la sociolinguistique}

Paris, Dunod, 2017, 140 p.

\section{Marielle Rispail}

\section{RÉFÉRENCE}

Henri Boyer, Introduction à la sociolinguistique, Paris, Dunod, 2017, 140 p.

1 C'est à une belle entreprise de réécriture et d'actualisation que s'est livré Henri Boyer avec cette Introduction à la sociolinguistique, dont la nouvelle version 2017 (la première date de 1991) lui a été demandée par l'éditeur, avec une petite marge de manœuvre pour la mettre au goût du jour et intégrer les évolutions de la discipline.

2 De fait, la filiation en même temps que la comparaison des deux ouvrages sont éclairantes. De même longueur (140 pages environ), ils comprennent tous deux, outre les chapitres de développement (3 grandes parties en 1991, 6 chapitres en 2017), une bibliographie sélectionnée (modernisée avec aplomb en 2017, pour les mêmes 8 pages) et un index épuré et rendu plus efficace en 2017 puisqu'il ne comprend que des notions et élimine les références aux auteurs.

3 Concernant les contenus, on retrouve les piliers de la sociolinguistique: la fondamentale variation, les contacts des langues, la « communication sociale » remplacée à bon escient par une réflexion sur les concepts de «communauté linguistique » et "marchés linguistiques ", l'omniprésence des représentations puis des stéréotypes. Mais la pensée se complexifie avec bonheur, malgré l'objectif de l'ouvrage qui reste d'initier des étudiant-e-s débutant-e-s à la sociolinguistique. C'est ainsi que des pans nouveaux de recherches sont pris en compte, comme l'importance prise par internet dans la vie des langues (p. 102), l'approche genrée dans la variation (p.44-48), le langage des banlieues avec la référence par exemple aux travaux de Lekha-Lemarchand, les notions de «parlers bilingues » ou de "mélanges de langues » qui n'étaient pas abordées dans le premier ouvrage, les problématiques de la migration (p. 89). On appréciera aussi un 
approfondissement de la réflexion sur le concept de «diglossie» avec ses prolongements et ses différentes interprétations (chapitre 4), l'élargissement du domaine sociolinguistique par l'ajout opportun du premier chapitre «La sociolinguistique : un autre regard sur le langage et les langues en sociétés ", la mise au pluriel de plusieurs notions et l'ouverture finale du chapitre 6 sur «Les politiques linguistiques». Il est intéressant en outre que l'étude des langues minorées s'intègre dans la réflexion sur le «contact des langues" et intègre une dynamique et nouvelle section sur « mort, résurrection, revitalisation, marchandisation ».

4 La cohérence d'ensemble est maintenue par la pensée «catalane » de la domination politique pour laquelle la prise en otage des langues de celui qu'on veut asservir, économiquement ou "imaginairement ", reste la voie royale. Et on se réjouit de la diversification des exemples choisis qui mènent à examiner des cas nouveaux de rencontres des langues, comme les créoles ou les pidgins.

5 Les esprits chagrins pourront regretter toutefois que des cas moins connus de minoration en France ne soient pas évoqués (on en reste aux emblématiques Catalogne et Occitanie), que certains auteur-e-s ne soient pas cité-e-s par leurs derniers ouvrages (L-J. Calvet, A. Tabouret-Keller par exemple) ou que les travaux corses soient à peu près ignorés (à part ceux de Marcellesi). Mais on ne peut que rester admiratif devant la clarté de cette $2^{\mathrm{e}}$ édition, qui a su faire des choix draconiens tout en proposant un portrait ouvert à l'écoute des questions vives de notre $\mathrm{XxI}^{\mathrm{e}}$ siècle, vues à travers les langues.

\section{AUTEURS}

\section{MARIELLE RISPAIL}

Université Jean Monnet - Saint-Étienne 